Çukurova Üniversitesi Mühendislik Mimarlık Fakültesi Dergisi, 31(ÖS 1), ss. ÖS 79-ÖS 88, Ağustos 2016 Çukurova University Journal of the Faculty of Engineering and Architecture, 31(ÖS 1), pp. SI 79-SI 88, August 2016

\title{
Saplama Kaynak Bağlantılarının Çekme Dayanımının ANFIS ile Modellenmesi
}

\author{
Necip Fazıl YILMAZ"1 ${ }^{*}$ M. Veysel ÇAKIR ${ }^{2}$, Musa YILMAZ $^{1}$ \\ ${ }^{1}$ Gaziantep Üniversitesi, Mühendislik Fakültesi, Makina Mühendisliği Bölümü, Gaziantep \\ ${ }^{2}$ Gaziantep Üniversitesi, Havacılık ve Uzay Bilimleri Fakültesi, Uçak Uzay Mühendisliği \\ Bölümü, Gaziantep
}

Geliş tarihi: 10.01.2016 Kabul tarihi: 04.04.2016

\section{Özet}

Saplama kaynak yönteminde istenilen özellikleri sağlayan iyi bir kaynak bağlantısı elde etmek için işlem parametrelerinin doğru ayarlanması gerekmektedir. Bunun için istenilen kalite özelliklerine sahip çıktı parametreleri ile girdi değişkenleri arasındaki karmaşık ilişkinin matematiksel olarak modellenmesine ihtiyaç duyulmaktadır. Bu makalede, saplama kaynak bağlantılarının çekme dayanımı tahmin eden bir model Adaptif Sinir Ağına Dayalı Bulanık Çıkarım Sistemi (ANFIS) ile geliştirilmiştir. Girdi parametreleri olarak saplama çapı, akım, zaman, kaldırma yüksekliği ve dalma miktarı alınmıştır. Geliştirilen bu model endüstride saplama kaynağı kullanıcılarına işlem parametreleri seçimi için bir rehber olacaktır.

Anahtar Kelimeler: Saplama kaynağı, Çekme dayanımı, Matematiksel modelleme, ANFIS

\section{ANFIS Modelling of the Tensile Strength of Arc Stud Welding Joints}

\begin{abstract}
In arc stud welding process, welding parameter set must be properly adjusted to obtain good welding joints which have desired properties. Therefore, it is needed to be mathematically modelling of the complex relationships between the input variables and output variables which have desired quality. In this article, a model that predicts the tensile strength of stud welding connections based on Adaptive Neural Network Fuzzy Inference System (ANFIS) was developed. Stud diameter, welding current, welding time, plunge and lift are taken as input parameters in this model. Developed model will be a guide for the selection of the process parameters for stud welding industry and its users.
\end{abstract}

Keywords: Stud welding, Tensile strength, Mathematical model, ANFIS

\footnotetext{
* Sorumlu yazar (Corresponding author) : N. Fazll YILMAZ, Mühendislik Fakültesi, Makina Mühendisliği Bölümü, Gaziantep.nfyilmaz@gantep.edu.tr
} 


\section{GíRiş}

Saplama kaynağı, genellikle cıvata veya özel olarak hazırlanmıș bir somunu elektrot olarak kullanarak saç veya levha şeklindeki bir iş parçasına birleştirme metodudur. Saplama kaynak ürünleri, endüstriyel ve ticari yapılar, köprüler, askeri araçlar, kazan üretimi, otomobil, kamyon, demiryolu, gemi yapımı, demiryolu araçları, elektrik parçaları, uçak, metal, mobilya ve diğer metal işleme sanayileri için kullanılır [1]. Bu metotta kaynak elemanları, ilave malzeme olmadan ve bağlama elemanlarını sabitlemek için herhangi bir delme, zımbalama, diş açma, yapıştırma ve perçinleme işlemi gerektirmeden sadece ark ile birleştirilir. Birçok alanda saplama kaynağı en ucuz birleştirme tekniğidir. Özellikle ince plakalarda, saplama kaynağı genellikle tek çözümdür.

Diğer kaynak işlemleriyle kıyasladığımızda, saplama kaynağı metodu, özellikle verimliliğinin giderek artması, kaynak hızı, otomasyona uygunluğu, ekipmanların kullanım kolaylığı, ucuzluk ve saplama lokasyonunun doğruluğu gibi birçok avantajlara sahiptir. Saplama kaynak işleminin bir diğer avantajı ise levhaya tek taraflı kaynak yapılabilirliğidir. Ayrıca, saplama kaynağı yüksek yük taşıma kapasitesine sahiptir ve kaynak işlemi sırasında akım, voltaj ve saplamanın hareketi monitörle izlenebilir [2].

Saplama kaynağı, diğer kaynak çeşitleriyle aynı elektriksel, 1sısal, metalürjik ve mekanik prensiplere haizdir [3]. Saplama kaynak işlemi birçok faktörden etkilenir, örneğin saplamanın tasarımı, malzeme tipi, levha malzemesinin kalınlığı, saplamanın kesit alanı, kaynak pozisyonu, yüzey durumu, çevresel koşullar ve kaynak parametreleri; kaynak akımı, kaynak süresi, kaldırma yüksekliği ve dalma miktarı gibi. Her bir faktörün kaynak kalite performansı üzerinde kendine özgü etkisi vardır[4].

Saplama kaynağı üzerine birçok araştırmalar yapılmıştır. Yılmaz ve Hamza [5] saplama kaynağının başarılı bir şekilde AISI 304 östenik paslanmaz çeliğe uygulanabileceğini gösterdiler. Yaptıkları çalışmada, farklı saplama çaplarına göre, ayarlanabilen kaynak parametreleri olan kaynak akımı, kaynak süresi, kaldırma yüksekliği ve dalma miktarı seviyelerini değiştirerek deneysel çalışmalar yaptılar ve kaynağın mekaniksel ve mikroyapısal özelliklerini araştırdılar. Kaynaklı parçaların çekme dayanımına etki eden en önemli kaynak parametrelerinin akım ve süre olduğunu, sonra kaynak dalma miktarı ve en az etkili olan parametrenin ise kaldırma yüksekliği olduğunu belirttiler.

Klaric ve arkadaşları [6] seramik halka ile yapılan çekmeli ark saplama kaynaklarında kaynak penetrasyon derinliğine kaynak parametrelerinin (akım, zaman, kaldırma yüksekliği ve dalma miktarı) etkisini araştırdılar. Samardzic ve arkadaşları [7] kaynak parametrelerinin penetrasyon derinliği ve sertleşmiş bölge uzunluğuna etkisini araştırdılar. Her iki çalışmada elde edilen sonuçlar, penetrasyon derinliğinin artmasında en etkili parametrenin kaynak akımı, sonra kaynak süresi, diğer iki faktörün ise daha az öneme sahip olduğunu göstermektedir.

Hamza [8] yaptı̆̆g çalışmada, kaynak parametrelerinin (akım ve zaman) malzemenin türüne, saplama ve ana malzemenin (kaynak sacı) boyutlarına bağlı olduğunu vurguladı. Fricke ve Tchuindjang [9] saplama ark kaynağının döngüsel yüklü başlıca gemi yapılarına (hollanda profilleri) uygulanabilirliğini, saplama çap1, kaynak pozisyonu ve diğer kaynak parametreleri değiştirerek yaptıkları birçok yorulma testleri ile kanıtladilar.

Diğer kaynak işlemlerinde olduğu gibi kaynak bağlantısının kalitesi kaynak parametrelerinin doğru seçimine ve kaynak işlemi sırasında tam olarak uygulanmasına bağlıdır. Ancak kaynak performansına etki eden birçok parametreler bulunmakta ve bu parametreler arasında genellikle lineer bir ilișki kurulamamaktadır. Bir sistemi etkileyen parametreler çok ve aralarındaki ilişki doğrusal değil ise aralarında matematiksel ilişki kurmak oldukça güçtür. Ancak, son y1llarda mühendislik alanında kullanımı hızla yaygınlaşan esnek hesaplama (matematiksel modelleme) yöntemleri non-lineer parametreler arasında ilişki kurmada da önemli mesafe kaydetmektedir. Birçok 
mühendislik problemleri doğal olarak karmaşık olduğundan, esnek hesaplama teknikleri genellikle bu tip problemlerde uygun çözümler sağlamaktadır.

Literatüre baktığımızda Ark saplama kaynağı işlemlerinde matematiksel modelleme çalışmalarına örnek olarak Hamza [10] 2011'de yaptığı çalışmayı örnek olarak verebiliriz. $\mathrm{Bu}$ çalışmada Hamza [10] ark saplama kaynağı ile yapılan bağlantıların, çekme dayanımı ile girdi parametreleri arasındaki karmaşık ilişkiyi bulmak için yapısal sinir ağı (YSA) tabanlı bir model geliştirdi. Bu modelde, bir çok katmanlı algılayıcı (MLP), geriye yayılma algoritması LevenbergMarquardt tarafindan örnek deneysel veriler kullanılarak eğitildi. Sonuçlar Taguchi deney tasarımı metodu ile karşılaştırıldı. YSA'nın ark saplama kaynağı performans çıtıları ile girdi parametreleri arasında doğrusal olmayan ilişki kurmada etkili bir araç olduğunu belirtti.

$\mathrm{Bu}$ çalışmada makine mühendisliği bölümünde, Ark saplama kaynak yöntemi ile yapılan deneysel çalışmalardan [5] elde edilen veriler kullanılarak adaptif ağ yapısına dayalı bulanık çıkarım sistemi (ANFIS) yöntemi ile saplama çapı göz önüne alınarak kaynak parametreleri olan; akım, zaman, kaldırma yüksekliği (lift) ve dalma miktarının (plunge), saplama kaynak bağlantılarının çekme dayanımı tahmin eden kullanıcı dostu bir model adaptif sinir ağına dayalı bulanık çıkarım sistemi (ANFIS) yöntemi ile geliştirilmiştir. $\mathrm{Bu}$ model endüstride saplama kaynağı kullanıcılarına işlem parametreleri seçimi için bir rehber olacaktır.

\section{ARK SAPLAMA KAYNAĞI}

Ark saplama kaynağı metal plaka ile cıvata, somun v.b. saplama parçalarının uç kısmının ark ile 1sınarak erimesi ve daha iyi birleşme ve katılaşma sağlanması için çubukların basınçla eriyiğe daldırılmasıyla ilave malzeme gerektirmeden oluşturulan bir kaynak yöntemidir. Çok sayıda ark saplama kaynağı tipleri bulunmasına rağmen, genel olarak kondansatör boşaltmalı (capacitor discharge (CD)) ve çekmeli (drawn arc (DC)) ark saplama kaynağı olarak sinıflandırılma yapılmaktadır. Hangi ürünün kaynak edileceği, uygulama alanı, kaynak edilecek parçaların malzemesi, saplama çapı ve plaka kalınlığı hangi tip kaynak türünün seçileceği konusunda önemli etkenlerdir [11].

Çekmeli ark saplama kaynağı çoğunlukla seramik halka ile yapılmakta ve $12 \mathrm{~mm}$ 'den büyük çaplı saplamalar için kullanılmaktadır, kaynak süresi 100 ila 1500 milisaniye'dir. Bu yöntem otomatik uygulamalar için uygundur.

Kondansatör boşaltmalı (CD) ark saplama kaynağı küçük çaplı parçaları (M3-M10) ince sac malzemelere (minimum kalınlık 0,6 $\mathrm{mm}$ ) uygulanmakta ve saç kalınlığının çapa oranı yaklaşık 1/10 olan uygulamalar yapılabilmektedir. Tüm kaynak süreci milisaniye içinde tamamlandığından dolayı, kaynaklar belirgin bozulma, yanma yada ters yönde renk değiştirme olmadan yapılabilir. Bağlantı elemanının bir ucu, bir CD kaynağı yapmak için tasarlanmış olduğu sürece, saplama parçalar hemen hemen tüm geometrik şekilleri için CD kaynağı yapılabilir.

\section{DENEYSEL ÇALIŞMALAR}

Ark saplama kaynağında kaynak performans kalitesini etkileyen birçok faktör bulunmaktadır. Dayanıklı kaynak bağlantıları elde etmek için, saplama kaynak parametrelerinin seçimine oldukça dikkat etmek gerekir. Her bir parametrenin kaynak bağlantısı üzerinde ayrı ayrı etkileri vardır. Bu çalışmada, önemli kaynak parametreleri olan; saplama çapı (D), kaynak akımı (I), kaynak süresi (T), daldırma miktarı (P) ve kaldırma yüksekliği (L) farklı seviyelerde alınarak (Çizelge 1), saplama kaynağ1 işlemleri, Şekil 1'de görülen düzenek kullanılarak yapılmış ve birleştirilen numunelerin çekme dayanımları ölçülmüştür (Çizelge 3-4). Saplama ve plaka malzemesi AISI 304 paslanmaz çelik olup, tüm deneylerde sac kalınlığı $5 \mathrm{~mm}$ olarak alınmıştır.

Mekanik testler, özellikle eksenel yük uygulanarak yapılan çekme testi, kaynak bağlantısı ve kaynak metalinin performanslarını değerlendirilmesinde, kaynak işleminin geliştirilmesi ve kaynak 
kalitesinin kontrol edilmesi açısından önemli rol oynamaktadır. Yüke maruz kalan bir mühendislik uygulamasında kullanılması planlanan kaynak bağlantısının, kaynak bölgesinin çalışma sırasındaki servis yüklere dayanıp dayanamayacağının bilinmesi gerekir, kaynaklık parçaların çekme testleri [12] bu açıdan önemlidir.

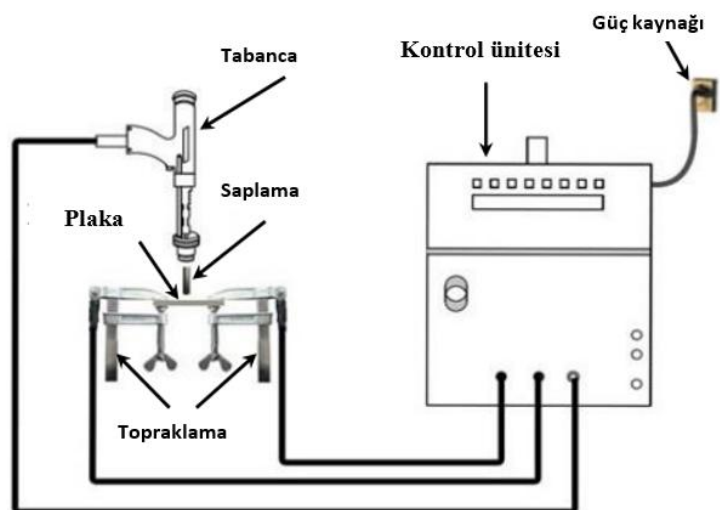

Şekil 1. Deney düzeneği [5]

$\mathrm{Bu}$ araştırmada kullanılan çekme test makinesi Şekil 2'de gösterilmektedir. Makinenin maksimum çekme yük kapasitesi 600 KN'dur. Kaynaklı numunelere tek eksenli yük, kopma gerçekleşene kadar uygulanmış ve çekme dayanımı kaydedilmiştir.

Çizelge 1. Kaynak parametreleri ve seviyeleri

\begin{tabular}{|l|l|l|}
\hline Parametre & Birim & Seviyeler \\
\hline $\begin{array}{l}\text { Saplama } \\
\text { çapı(d) }\end{array}$ & $\mathrm{mm}$ & $6,8,10,12$ \\
\hline $\begin{array}{l}\text { Kaynak } \\
\text { akımı(I) }\end{array}$ & Amper & $\begin{array}{l}300,400,500, \\
600700,800, \\
900,1000\end{array}$ \\
\hline $\begin{array}{l}\text { Kaynak } \\
\text { süresi(T) }\end{array}$ & Saniye & $0,1 \quad 0,2 \quad 0,3 \quad 0,4$ \\
\hline $\begin{array}{l}\text { Daldırma } \\
\text { miktarı(P) }\end{array}$ & $\mathrm{mm}$ & $1,2,3,4$ \\
\hline $\begin{array}{l}\text { Kaldırma } \\
\text { yüksekliği(L) }\end{array}$ & $\mathrm{mm}$ & $1,522,53$ \\
\hline
\end{tabular}

Kaynak numunelerinin bir tarafı saplama ve diğer tarafı plaka olduğundan dolayı, numuneler standart çekme çenelerine bağlama için uygun değildir. $\mathrm{Bu}$ nedenle kaynak numunelerinin çekme testini yapmak için özel bir bağlama aparatı kullanılmıștır (Şekil 2).

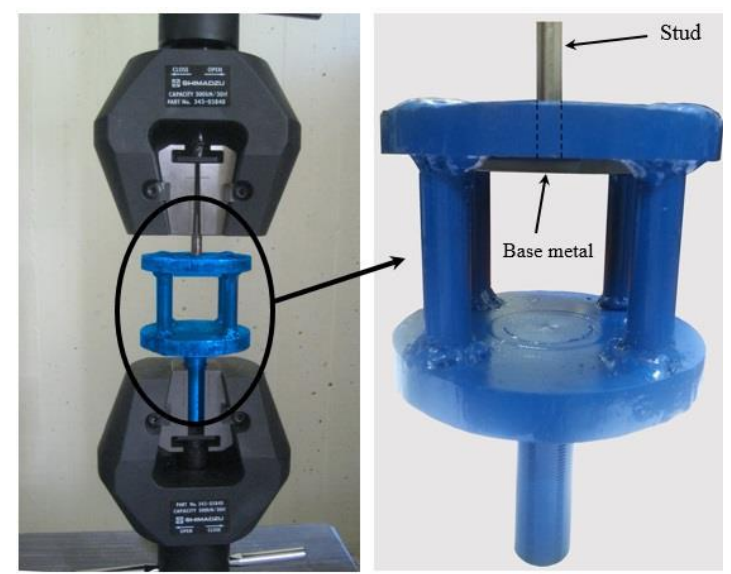

Şekil 2. Özel bağlama aparatı ve çekme testinin yapılışı

\section{ADAPTIF AĞ TEMELLI BULANIK MANTIK ÇIKARIM SİSTEMI}

Adaptif ă̆ temelli bulanık mantık çıkarım sistemi (ANFIS), yapay sinir ağlarının (YSA) öğrenme yeteneği ile bulanık mantığın insan gibi karar verme özelliklerinin birleşmesi ile ortaya çıkan melez bir modeldir [13]. Bulanık mantık ve yapay sinir ağları belirsizlikler için uygun bir çözüm sunabilen 2 farklı yöntemdir. Bulanık mantık ve YSA'nın uygun birleşimi (hybridization) ile geliştirilen hibrit bir yöntem olan ANFIS, birisinin üstünlüğü ile diğerinin zayıflığının üstesinden gelmeye olanak sağlar. Bu sayede, farklı alanlara ait geniş problem yelpazesine uygun çözümler bulunabilir [14;15]. Şekil 3'te görüldüğüü üzere ANFIS model sistemi, bulanık çıkarım sistemi ile adaptif ağların bütünleşmiş halidir.

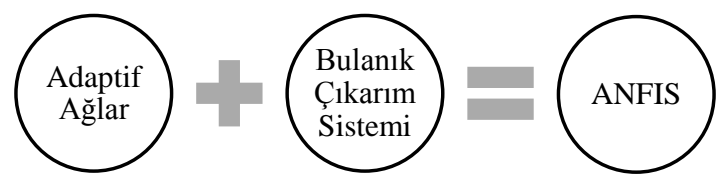

Şekil 3. ANFIS model sistemi 
Adaptif ağ, çeşitli sayıda birbirine bağlanmış düğümler içeren, eldeki girdi ve çıktı veri setini ortaya koymaya yarayan ağ yapısını ifade eder [16]. Adaptif ağlardaki düğümler arası bağlantılar, birleştirilen düğümlerle aradaki nedensellik ilişkisini belirtir. Bulanık çıkarım sistemleri ise, giriş değişkenlerinin çıkış değişkenlerine dönüşümünde bulanık kümeleri sunan sistemlerdir [17]. Bulanık sistemler; sayısal olarak ifade edilemeyen, belirsiz şartlar altında insan gibi hareket eden sistemlerdir. Bulanık çıkarım sistemleri için çok sayıda, farklı modeller geliştirilmiştir. Mamdani, Tsukamoto ve Sugeno tipi çıkarım sistemleri bu modellerden birkaç tanesi olarak sayılabilir. Sugeno tipi çıkarım sistemi, girdi ve çıktı veri setlerine göre bulanık kuralların oluşturulması için sistematik yaklaşım sağlayan bir sistemdir. İlk olarak 1993 yılında ortaya çıkarılan Jang'ın ANFIS modeli de insan gibi karar vermede "Sugeno Bulanık Mantık Çıkarım Sistemini”" esas alır. Jang, çalışmasında doğrusal olmayan üyelik fonksiyonlarının modellenmesi ve kaotik zaman serilerinin tahmin edilmesi için ANFIS'i geliştirmiştir [18].

ANFIS öğrenme yöntemi YSA'larına benzer şekilde çalışır. ANFIS sistemlerde, verilen giriş/çıkış veri kümesi kullanılarak, üyelik fonksiyonları parametreleri; ya yalnızca bir geriyayılım algoritması ile ya da en küçük kareler yöntemi ve geriyayılım algoritmasının birleşimi (hibrit) ile ayarlanır [18]. $\mathrm{Bu}$ ayarlamalar, modellenecek verilerden bulanık sisteminin eğitilmesine olanak sağlar.

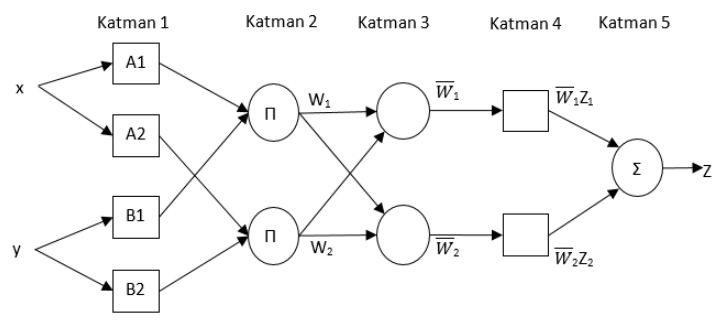

Şekil 4. Tipik bir ANFIS mimarisi [18]

2 giriş verisine sahip ( $\mathrm{x}$ ve $\mathrm{y}$ ), düğüm fonksiyonu ile ilişkili dilsel etiketleri (A1, A2, B1 ve B2), normalize edilmiş ateşleme dayanımı (Wi) ve düğüm etiketi (П) olan tipik bir ANFIS mimarisi Şekil 4'te görülmektedir. ANFIS, 5 katmanlı ileri beslemeli ağ yapısına sahip Sugeno-tipi bir bulanık sistemdir. Birinci katmada bulanıklaştırma işlemi gerçekleştirilir, ikinci katman kural katmanıdır ve bu katmandaki her bir nöron basit Sugeno-tip bulanık bir kuralı temsil eder. Üçüncü katmanda üyelik fonksiyonları normalleştirilir. Kuralların sonuçlandırma kısımlarının çalıştırıldı ğı yer durulama katmanı olan 4. Katmandır. 5. Katman tüm giriş sinyallerinin toplamı olarak tüm anfis çıkışlarını hesaplar [19].

\subsection{ANFIS Modelinin Olușturulması}

$\mathrm{Bu}$ çalışmada, ANFIS modelini oluşturmada MATLAB'ın ANFIS araç kutusu kullanılmıştır. $\mathrm{Bu}$ araç kutusu, bir geri yayılım algoritması ve/veya en küçük kareler yöntemi ile birlikte kullanılarak fuzzy sistemler oluşturmaya yardımcı olur. ANFIS modellerinde, deneysel verilerin, $\% 73$ 'i eğitim (train) ve $\% 27$ 'i ise test veri dataları olarak rastgele seçilmiş ve programa yüklenmiştir (Çizelge 3-4). Buna göre Çekme dayanımı modelinin oluşturulması için 33 adet öğrenme ve 12 adet test verileri oluşturulmuştur.

Eğitim verisi dışında oluşturulan bir kontrol veri kümesi, ANFIS modeli genelleme yeteneklerini doğrulamak için uygulanır. ANFIS eğitimi için verilen bir giriş/çıkış verisi üzerinde eksiltmeli kümeleme uygulanarak model tarafindan bir başlangıç bulanık çıkarım sistemi (FIS) oluşturulur. Hibrit öğrenme algoritması kullanılarak hılı bir parametre tanılanması gerçekleşir böylece yakınsamaya yaklaşması için gerekli zaman azaltılmış olur. Minimum doğrulama hatası ise aşırı uyumdan kaçınmak için durdurma kriteri olarak kullanılır.

ANFIS ile kurulan modeller, elde bulunan girdiçıktı setine uygun üyelik fonksiyonu ve kurallar ile belirlenmektedir. Uygun üyelik fonksiyonunun belirlenmesi sürecinde, her bir fonksiyon için hesaplanan eğitim ve test verilerinin sonuçları incelenmiş, modellerin kurulmasında en düşük hata payını veren üyelik fonksiyonları (MFS) uygun görülmüştür. Üyelik fonksiyonu sayısının 
belirlenmesinde ise veri setinin eğitilecek parametre sayısından fazla olması gerektiği hususu göz önüne alınmıştır.

\section{BULGULAR VE TARTIŞMA}

\subsection{Model Performans Kriterleri}

Bir modelleme işleminin performansı; geliştirilen model tarafindan temsil edilen gerçek sistemin, belli bir girdi değerine karşılık ürettiği çıktı değeri ile modelin aynı girdiye karşılık ürettiği çıktı arasındaki farkın (hata) temel alındığı çeşitli tanımlamalara göre belirlenir [20]. Modellerin hassasiyeti doğruluğu bu istatistiksel verilere göre değerlendirilmektedir.

Hata kareleri ortalaması (Mean Square Error MSE) bunlardan bir tanesidir. MSE fonksiyonu istenen sonuç ile hesaplanan sistem çıkışı arasındaki farkın kareleri toplamının ortalaması olup aşağıdaki formülle hesaplanır:

$M S E=\frac{1}{N} \sum_{i=1}^{N}\left(d_{i}-y_{i}\right)^{2}$

Burada $d_{i}$, istenen çıkış değerini, $y_{i}$ ise modelleme programı tarafından hesaplanan çıkış değerini ifade eder. $\mathrm{N}$ ise çıkış hücre sayısını belirtmektedir. Hata kareleri ortalamasının sifira yaklaşması modelin tahmin kabiliyetinin artması anlamina gelmektedir [21].

Model performanslarının karşılaștırılması için kullanılan ölçütlerden biri de, ortalama mutlak hata (Mean Absolute Error-MAE)'dır. Aşağıdaki şekilde hesaplanır:

MAE $=\frac{\sum_{1}^{\mathrm{N}}\left|\mathrm{x}_{\mathrm{i}}-\mathrm{y}_{\mathrm{i}}\right|}{\mathrm{N}}$

MSE ve MAE sonuçları ne kadar düşükse modellerin performansı o ölçüde iyi olduğu söylenebilir. Çünkü hata paylarının düşük çıkması tahmin edilen değerler ile gerçekleşen değerler arasındaki sapmanın düşük olduğu anlamına gelmektedir.

Belirlilik katsayısı $\mathrm{R}^{2}$ (korelasyon katsayısının karesi) deneylerden elde edilen veriler ile geliştirilen modellerin tahminleri arasında doğrusal bir ilişki olup olmadığını belirlemek amacıyla

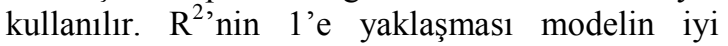
tahmin ettiğini 0 'a yaklaşması ise tahminin kötü olduğunu göstermektedir. $\mathrm{R}^{2}$ korelasyon katsayısının karesi olup aşağıdaki şekilde hesaplanmaktadir [22].

$R^{2}=\left[\frac{\sum(x-\bar{x})(y-\bar{y})}{\sqrt{\sum(x-\bar{x})^{2} \sum(y-\bar{y})^{2}}}\right]^{2}$

Çizelge 2. ANFIS mimarisi ve öğrenme parametreleri

\begin{tabular}{|l|c|c|c|}
\hline $\begin{array}{l}\text { Üyelik Fonksiyon } \\
\text { (MF) sayıs }\end{array}$ & $\mathbf{2 2 3 2 2 3}$ & $\mathbf{3 4 2 2 2} 2$ & $\mathbf{3 ~ 3 3 ~ 3 ~ 3}$ \\
\hline $\begin{array}{l}\text { Üyelik fonksiyon } \\
\text { (MF) tipi }\end{array}$ & Trimf & Gbell & Gauss \\
\hline Düğüm sayıs1 & 176 & 226 & 524 \\
\hline $\begin{array}{l}\text { Lineer parametre } \\
\text { sayıs1 }\end{array}$ & 432 & 576 & 1458 \\
\hline $\begin{array}{l}\text { Non-lineer parametre } \\
\text { sayıs1 }\end{array}$ & 36 & 39 & 30 \\
\hline $\begin{array}{l}\text { Toplam parametre } \\
\text { sayıs1 }\end{array}$ & 468 & 615 & 1488 \\
\hline Bulanık kural sayısı & 72 & 96 & 243 \\
\hline
\end{tabular}

\subsection{ANFIS Modelleme Sonuçları}

ANFIS araç kutusunda birçok farklı üyelik fonksiyonları olmakla birlikte; trimf, trapmf, gauss, ve gbell üyelik fonksiyonları çoğunlukla kullanılan üyelik fonksiyonlarındandır. $\mathrm{Bu}$ çalışmada yapılan denemelerde Trimf, gaussian ve gbell üyelik fonksiyonlarının modeller için daha iyi sonuçlar verdiği görüldü. Üyelik fonksiyon sayılar1 ise 2-2-2-2-2 ten 5-5-5-5-5'e kadar değiştirilerek çok sayıda denemeler yapıldı.

Deneme ve yanılma metodu ile tüm üyelik fonksiyonları denendikten sonra elde edilen en iyi üyelik fonksiyon tipleri ve sayılarına ulaşıldığında elde edilen ANFIS mimarisi ve öğrenme parametreleri Çizelge 2'de görüldüğü gibi elde edildi. Elde edilen en iyi modellerin tahmini değerleri ile deneysel verilerin sonuçları (Çizelge 4 ve 5)'te verilmektedir. 

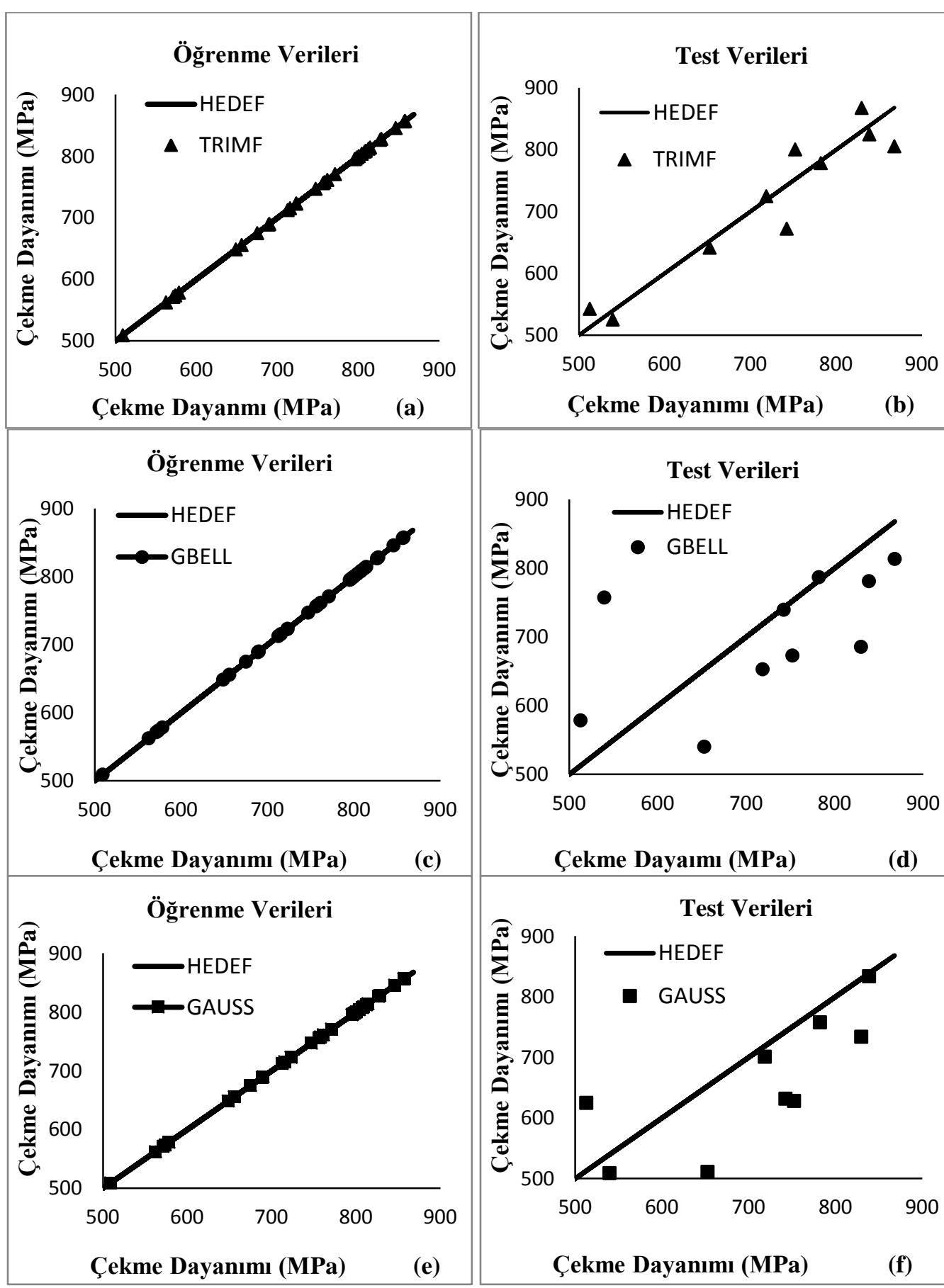

)

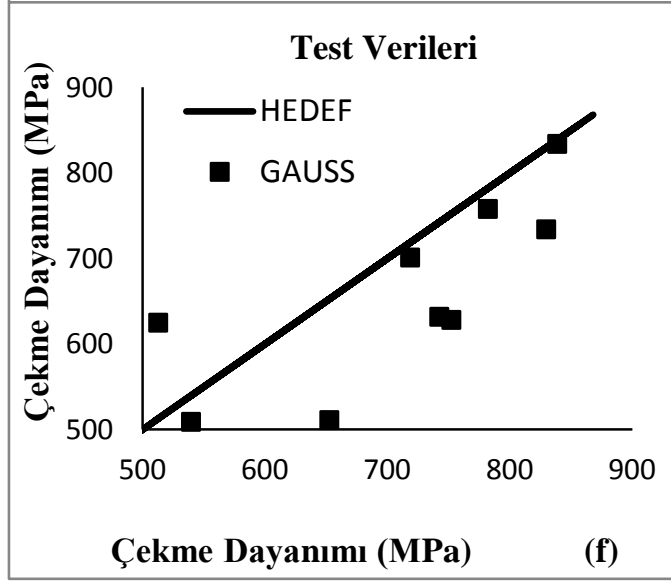

Şekil 5. ANFIS modellerinin eğitim ve test performanslarının deneysel verilerle karşılaştııılması (a) trimf eğitim (b) trimf test (c) gbell eğitim (d) gbell test (e) gauss eğitim (f) gauss test grafiği 
Çizelge 3. ANFIS modellerinin tahmini eğitim verileri ile deneysel sonuçları

\begin{tabular}{|c|c|c|c|c|c|c|c|c|}
\hline \multicolumn{6}{|c|}{ Girdi Parametreleri } & \multicolumn{4}{c|}{ Sonuçlar } \\
\cline { 6 - 9 } & & I & T & P & L & Deysel & \multicolumn{3}{|c|}{ Modelleme } \\
\hline 6 & 300 & 0,3 & 3 & 2,5 & 798,5 & Trimf & Gbellmf & Gaussmf \\
\hline 6 & 300 & 0,4 & 4 & 3 & 655,9 & 655,9 & 798,5 & 798,4 \\
\hline 6 & 400 & 0,2 & 1 & 3 & 807,7 & 807,7 & 855,9 & 655,9 \\
\hline 6 & 400 & 0,4 & 3 & 2 & 573,9 & 573,9 & 573,9 & 807,7 \\
\hline 6 & 500 & 0,2 & 4 & 2,5 & 800,4 & 800,4 & 800,4 & 873,9 \\
\hline 6 & 500 & 0,3 & 1 & 2 & 578,5 & 578,5 & 578,5 & 578,4 \\
\hline 6 & 300 & 0,1 & 1 & 1,5 & 648,7 & 648,7 & 648,7 & 648,7 \\
\hline 6 & 600 & 0,2 & 3 & 1,5 & 571,5 & 571,5 & 571,6 & 571,5 \\
\hline 12 & 900 & 0,4 & 2 & 1,5 & 796,5 & 796,4 & 796,4 & 796,5 \\
\hline 8 & 500 & 0,1 & 1 & 1,5 & 828,3 & 828,3 & 828,4 & 828,3 \\
\hline 8 & 500 & 0,2 & 2 & 2 & 857,5 & 857,5 & 857,5 & 857,5 \\
\hline 8 & 500 & 0,4 & 4 & 3 & 690,1 & 690,1 & 690,0 & 690,0 \\
\hline 8 & 600 & 0,1 & 2 & 2,5 & 757,9 & 757,9 & 757,9 & 757,9 \\
\hline 8 & 700 & 0,2 & 4 & 2,5 & 845,9 & 845,9 & 845,9 & 845,9 \\
\hline 8 & 700 & 0,4 & 2 & 1,5 & 509,2 & 509,2 & 509,2 & 509,2 \\
\hline 8 & 800 & 0,1 & 4 & 2 & 761,6 & 761,6 & 761,6 & 761,5 \\
\hline 8 & 800 & 0,2 & 3 & 1,5 & 723,3 & 723,3 & 723,3 & 723,4 \\
\hline 8 & 600 & 0,2 & 1 & 3 & 747,2 & 747,2 & 747,2 & 747,1 \\
\hline 10 & 600 & 0,1 & 1 & 1,5 & 689,1 & 689,1 & 689,1 & 689,0 \\
\hline 10 & 600 & 0,4 & 4 & 3 & 809,1 & 809,1 & 809,0 & 809,0 \\
\hline 10 & 700 & 0,2 & 1 & 3 & 856,7 & 856,7 & 856,8 & 856,7 \\
\hline 10 & 700 & 0,3 & 4 & 1,5 & 804,1 & 804,1 & 804,1 & 804,2 \\
\hline 10 & 900 & 0,2 & 3 & 1,5 & 771,1 & 771,1 & 771,1 & 771,1 \\
\hline 10 & 900 & 0,3 & 2 & 3 & 712,7 & 712,7 & 712,7 & 712,6 \\
\hline 12 & 700 & 0,1 & 1 & 1,5 & 562,5 & 562,5 & 562,5 & 562,5 \\
\hline 12 & 700 & 0,3 & 3 & 2,5 & 814,4 & 814,3 & 814,4 & 814,4 \\
\hline 12 & 700 & 0,4 & 4 & 3 & 812,5 & 812,5 & 812,5 & 812,4 \\
\hline 12 & 800 & 0,1 & 2 & 2,5 & 675,1 & 675,1 & 675,1 & 675,1 \\
\hline 12 & 800 & 0,2 & 1 & 3 & 756,3 & 756,3 & 756,3 & 756,3 \\
\hline 12 & 900 & 0,1 & 3 & 3 & 715,6 & 715,6 & 715,6 & 715,5 \\
\hline 12 & 1000 & 0,1 & 4 & 2 & 723,1 & 723,1 & 723,1 & 723,0 \\
\hline 12 & 1000 & 0,3 & 2 & 3 & 826,8 & 826,8 & 826,8 & 826,8 \\
\hline 12 & 1000 & 0,4 & 1 & 2,5 & 795,3 & 795,3 & 795,3 & 795,5 \\
\hline
\end{tabular}

Belirlilik katsayısı $\left(\mathrm{R}^{2}\right)$ değeri 0,7 ila 1 arasında ise modelin istenilen çıktı performans değerini tahmin etmede iyi olduğu $0,7^{\prime}$ den küçük ise yeterli olmadı̆̆ 1 ifade edilmektedir. Eğitim verilerinin istatistiksel sonuçlarına bakıldığında tüm fonksiyon tiplerinin öğrenme yeteneklerinin oldukça yüksek olduğu görülmektedir (Çizelge 3). Ancak test verilerine bakıldığında, Trimf ve gauss fonskiyon tipi ile üretilen modellerin sirasiyla belirlilik katsayılarının $\left(\mathrm{R}^{2}\right) 0,87$ ve 0,82 olduğu Gbell fonksiyon tipi ile elde edilen modelin ise belirlilik katsayısının 0,65 olduğu dolayısıyla en iyi tahmin eden modelin Trimf daha sonra gauss ile elde edilen model olduğu, ancak gbell ile oluşturulan modelin ise yeterli olmadığ görülmektedir. 
Modellerin tahmin sonuçları ile deneysel sonuçlarının karşılaştırmaları hem eğitim hem de test verileri için grafiksel olarak Şekil 5'te verilmektedir. Bu grafiklere bakıldığında deneysel veriler ile modellerden elde edilen tahmini değerler arasında eğitim verileri açısından çok az bir sapma olduğu görülmektedir (Şekil 5a, c ve e). Buna karşın test verileri açısından ise en az sapmaya sahip olan modelin trimf (Şekil 5b) daha sonra gaus (Şekil 5f) olduğu gbel modelinde ise sapmanın oldukça fazla olduğu görülmektedir.

Çizelge 4. ANFIS modellerinin tahmini test verileri ile deneysel sonuçları

\begin{tabular}{|c|c|c|c|c|c|c|c|c|}
\hline \multicolumn{4}{|c}{ Girdi Parametreleri } & \multicolumn{5}{c|}{ Sonuçlar } \\
\cline { 6 - 9 } & Deneysel & \multicolumn{3}{|c|}{ Modelleme } \\
\hline D & I & T & P & L & S $_{\text {UT }}$ & Trimf & Gbellmf & Gaussmf \\
\hline 6 & 300 & 0,2 & 2 & 2 & 718,7 & 724,8 & 652,9 & 701,3 \\
\hline 6 & 600 & 0,3 & 2 & 3 & 419,8 & 550,2 & 486,5 & 348,2 \\
\hline 8 & 500 & 0,3 & 3 & 2,5 & 829,8 & 867,7 & 685,5 & 734,2 \\
\hline 8 & 600 & 0,3 & 4 & 1,5 & 742,5 & 672,3 & 739,5 & 632,0 \\
\hline 8 & 800 & 0,3 & 2 & 3 & 539,6 & 525,3 & 757,3 & 509,1 \\
\hline 10 & 600 & 0,2 & 2 & 2 & 868,0 & 805,6 & 813,4 & 953,4 \\
\hline 10 & 600 & 0,3 & 3 & 2,5 & 838,8 & 824,9 & 781,0 & 834,1 \\
\hline 10 & 900 & 0,1 & 4 & 2 & 782,2 & 778,4 & 786,9 & 758,0 \\
\hline 12 & 1000 & 0,2 & 3 & 1,5 & 752,3 & 800,6 & 672,8 & 628,3 \\
\hline 10 & 800 & 0,4 & 2 & 1,5 & 652,7 & 641,6 & 540,2 & 511,1 \\
\hline 6 & 500 & 0,4 & 2 & 1,5 & 405,1 & 309,2 & 406,6 & 293,0 \\
\hline 8 & 700 & 0,3 & 1 & 2 & 512,8 & 542,7 & 578,5 & 625,1 \\
\hline
\end{tabular}

\section{SONUCCLAR}

$\mathrm{Bu}$ çalışmada, ark saplama kaynak bağlantıları; saplama çapı (D), kaynak akımı (I), kaynak süresi (T), daldırma miktarı $(\mathrm{P})$ ve kaldırma yüksekliği (L) farklı seviyelerde alınarak 45 farklı çekme deneyi yapılmıştır. Daha sonra, deneysel çalışmalardan elde edilen veri setleri, adaptif sinir ağına dayalı bulanık çıkarım sistemi (ANFIS) modellerini geliştirmek için kullanılmıştır. ANFIS modelleri MATLAB'ın ANFIS araç kutusu ile oluşturulmuştur. Trimf, Gaus ve Gbell fonksiyon tipleri kullanılarak ve bunların fonksiyon sayıları değiştirilerek çok sayıda denemeler yapılmıştır. Modellerin hassasiyeti ve doğruluğu $\mathrm{R}^{2}$, MAE ve MSE gibi istatistiksel verilere göre değerlendirilmiş aşağıdaki sonuçlara ulaşılmıştır.

- Eğitim verilerinin istatistiksel sonuçlarına bakıldığında tüm fonksiyon tiplerinin öğrenme yeteneklerinin oldukça yüksek olduğu görülmektedir.
- En iyi model, Trimf fonksiyon tipi ve fonksiyon sayıs 2-2-3-2-3 olan modeldir ve istatistiksel değerleri; $\mathrm{R}^{2}=0,87, \mathrm{MAE}=43,67$ ve $\mathrm{MSE}=3353,66$ 'dır.

- Gauss fonksiyon tipi ve fonksiyon sayıs1 3-3-3-3-3 olan model ikinci iyi model olup istatistiksel değerleri; $\mathrm{R}^{2}=0,82, \mathrm{MAE}=77,49$ ve $\mathrm{MSE}=8016,1^{\prime} \mathrm{dir}$

- Gbell fonksiyonu ile elde edilen modelin belirlilik katsayısı $\mathrm{R}^{2}$ değeri 0,7'nin altında olduğundan uygun olmadığı görülmektedir.

Ark saplama kaynağı kullanıcıları, dayanıklı (çekme dayanımı) bir kaynak bağlantısı elde etmek için ANFIS ile oluşturulan yukarıdaki modelleri kullanarak, saplama çapı için uygun olan kaynak parametre seti değerlerini seçebilir. 


\section{KAYNAKLAR}

1. http://www.nelsonstud.com/portal/

2. Behrens B.A., Gruß D., Jenicek A., 2011. Stud welding within sheet metal working tools. Prod. Eng. Res. Devel. pp. 283-292.

3. Hildebrand J., Soltanzadeh H., 2014. A Review on Assessment of Fatigue Strength in Welded Studs. International Journal of Steel Structures. pp. 421-438.

4. Hamza A.A., 2014. Investigation of the Effect of Parameters on Mechanical and Microstructural Properties of Arc Stud Welding. MSc thesis in Mechanical Engineering in Gaziantep University.

5. Yilmaz N.F., Hamza A.A., 2014. Effect of Process Parameters on Mechanical and Microstructural Properties of Arc Stud Welds. Materials Testing pp: 806-811.

6. Klaric S., Kladaric I., Kozak D., Stoic A., Ivandic Z., Samardzic I. 2009. The Influence of the Stud Arc Welding Process Parameters on the Weld Penetration. Fascicle: Mechanics. Tribology. Machine Manufacturing Technology. Series C. pp. 79-84.

7. Samardzic I., Kladaric I., Klaric S. 2009. The Influence of Welding Parameters on Weld Characteristics in Electric Arc Stud Welding. Metalurgija pp. 181-185.

8. Hamza R.M.A., 2012. Optimized stud arc welding process control factors by Taguchi experimental design technique. Gulf University, Chapter 15. pp. 369-394. Kingdom of Bahrain.

9. Fricke W., Tchuindjang D.D. 2013. Fatigue strength behaviour of stud-arc welded joints in load-carrying ship structures. Weld World pp.495-506.

10. Hamza R.M.A. 2011. Multi-objective neural network modelling for improving stud arc welding process joining. Journal of Engineering Science and Technology. pp. 382 -391 .

11. Hsu C., Mumaw J., 2011. Weldability of advanced high strength steel drawn arc stud welding. Welding Journal pp. 45-53.
12. Davis, J.R., 2004. Second edition Tensile Testing. ASM International, United States of America.

13. Elmas, Ç., 2003. Bulanık Mantık Denetleyiciler (Kuram, Uygulama, Sinirsel Bulanık Mantık). Seçkin Yayıncılık.

14.Jang, J.S.R., Sun, C.T., Mizutani, E., 1997. Neuro-fuzzy and soft computing: a computational approach to learning and machine intelligence. Prentice Hall, Inc.

15. Kim, J., Kasabov, N., 1999. ANFIS: Adaptive Neurofuzzy inference systems and their application to nonlinear dynamical systems. Neural Networks. pp. 1301-1319.

16. Yücel, A., Güneri, A.F., 2010. Application of Adaptive Neuro Fuzzy Inference System to Supplier Selection Problem. Journal of Engineering and Natural Sciences, pp. 224234.

17. Subaşı, S., Şahin, İ., Çomak, B., 2010. Tahribatsız Test Sonuçları Kullanılarak Uçucu Kül İkameli Betonlarda Basınç Dayanımının ANFIS ile Tahmini. International Journal of Technologic Sciences pp. 9-16.

18. Jang, J.S.R., 1993. ANFIS: Adaptive-networkbased fuzzy inference systems. IEEE Trans. Syst. Man Cybern pp.665-685.

19. Sugeno, M., Kang, G.T., 1988. Structure identification of fuzzy model. Fuzzy Sets and Systems. pp.15-33.

20. Demirel, Ö., 2009. ANFIS ve ARMA Modeller İle Elektrik Enerjisi Yük Tahmini. Marmara Üniversitesi Fen Bilimleri Enstitüsü Yüksek Lisans Tezi.

21.Singh, K. P., Basant, A., Malik, A., Jain, G., 2009. Artificial neural network modeling of the river water quality - a case study. Ecological Modelling. pp. 888-895.

22. Doğan, E., Ateş, A., Yılmaz, E.C., Eren, B. 2008. Application of Artificial Neural Networks to Estimate Wastewater Treatment Plant Inlet Biochemical Oxygen Demand. Environmental Progress. pp. 439-446. 